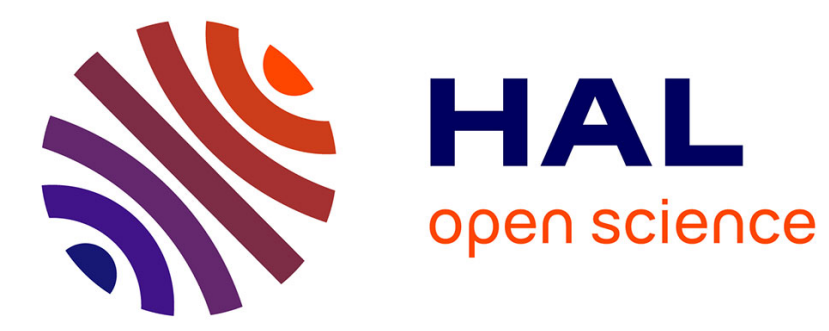

\title{
The use of Twitter in promoting digital libraries: a case study of QDL \\ Maha Alsarraj
}

\section{To cite this version:}

Maha Alsarraj. The use of Twitter in promoting digital libraries: a case study of QDL. ELPUB 2020 24rd edition of the International Conference on Electronic Publishing, Apr 2020, Doha, Qatar. 10.4000/proceedings.elpub.2020.6 . hal-02544254

\section{HAL Id: hal-02544254 \\ https://hal.science/hal-02544254}

Submitted on 16 Apr 2020

HAL is a multi-disciplinary open access archive for the deposit and dissemination of scientific research documents, whether they are published or not. The documents may come from teaching and research institutions in France or abroad, or from public or private research centers.
L'archive ouverte pluridisciplinaire HAL, est destinée au dépôt et à la diffusion de documents scientifiques de niveau recherche, publiés ou non, émanant des établissements d'enseignement et de recherche français ou étrangers, des laboratoires publics ou privés. 


\title{
The use of Twitter in promoting digital libraries: a case study of QDL
}

\author{
Maha Alsarraj
}

\section{Background}

1 Twitter is one of the most useful platform that any digital library can use in marketing its activities. Qatar Digital Library has low engagement rate in Twitter as it is not using the platform effectively. As a result, QDL is not effectively using Twitter in marketing its content. Similar libraries like BL Labs have a well-developed Twitter presence while QDL is still lacking behind. An example of this is that BL Labs has more followers in Twitter than QDL and its engagement rate is higher than that of QDL. Thus, this paper also seeks to identify the reasons that make QDL's Twitter account have low engagement rate as compared to BL Labs and Europeana.

2 In this paper, we explore use of Twitter in digital libraries. Analysing Twitter is easy because it has an open API that allows access of data about the tweets, as well as retweets, and so exploring and analysing account performance is easy (Demirbas et al., 2010). In regard to that, the paper will focus on BL Labs, Europeana, and QDL. As a result, this paper seeks to identify ways that QDL can use to boost its marketing in Twitter, which will then lead to growth in its Twitter following.

\section{Key Objective and Significance of the Study}

3 The aim of this paper is to establish the steps that Qatar Digital Library can take to help with the engagement rate in its Twitter content. The paper will mainly undertake comparative analysis of the Twitter accounts of BL Labs, Europeana, and QDL. By comparing Twitter feeds and activities of BL Labs and Europeana with that of QDL, the paper will recommend changes that QDL needs to make in its Twitter account to get a much higher engagement rate and better marketing. 
The paper's objective is to evaluate how Qatar Digital Library can use Twitter better in marketing its online content and how it can engage better with its users. To achieve this objective, QDL's activities in Twitter will be compared to that of BL Labs and Europeana so that areas that QDL is making mistake will be identified and needed changes will then be given out.

5 This study is significant as it fosters to change the current performance of QDL in social platforms. By recommending areas that QDL is failing in Twitter as well as other recommendations based on the type of platform, this paper will be essential in ensuring that QDL succeeds in marketing its content using social media platforms. In addition, this paper will be instrumental in driving other digital libraries within the region towards their success in social media marketing and building a strong online community of users.

\section{Methodology}

6 In this work, we are using various analytic tools. Google Trend is essential is checking out how the QDL, Europeana, and BL Labs are trending. Twitter archiver will be used to archive tweets, and then use Tag Crowd tool to create word cloud for the tweets. Social Bakers will be used in comparing performance of QDL to that of the Europeana as well as BL Labs. Lastly, the tweets will be analyzed in terms of retweets and engagement rate using the Followerwonk tool. So, a comparative analysis of the Twitter feeds of the three digital libraries: BL Labs, QDL, and Europeana, will be performed using engagement metrics. Using analytic tools, the best decision will be arrived at and that decision will aim at making QDL project more successful in its social media platforms especially Twitter marketing.

\section{Overview}

7 In spite of an increase in social media usage by digital libraries across the world, its use by digital libraries from Qatar is still low. Twitter is continuing to receive new users and the digital libraries in this platform are also benefiting from the new online users. In that case, QDL has to embrace and devise ways to utilize this platform fully. After looking at different literature material, no single material looks at how QDL can improve its Twitter engagement rate and following just like BL Labs and Europeana.

Qatar National Library partnership with the British Library including Qatar Foundation led to QDL project. The purpose of this project was to digitize the collection (Medawar \& Tabet, 2016). Today QDL has played a key role in making the ancient collection in the Gulf region accessible online to users across the world (Davies, 2018). However, its growth rate in social media platforms is considerably low unlike it was anticipated when it was founded. This problem is what this project intends to address.

Another notable problem is that is not easy to find official account of QDL in Twitter because the name that QDL uses is different. QDL's official Twitter account name is BL Qatar Partnership. Besides that, other issues like how QDL posts its content online and how it interacts with its users in Twitter are key issues that affect its engagement rate and following number. The next section shows the outcome of this study. 


\section{Outcomes}

10 Among the key outcome of the analysis undertaken is retweet rate. According to Soboleva (2018), retweet rate is essential as it among the key factor that determines the engagement rate as it measures the rate at which users consumer the content posted. Regarding the retweets, QDL has 17\%, followed by Europeana with 53\% and BL Labs has the highest retweets rate of $83.5 \%$ (Figure 1). Consequently, the engagement rate for QDL is $25 \%$ while European and BL Labs is $62.5 \%$ and $99.5 \%$ respectively (Figure 2).

Figure 1. Summary of Tweeter details

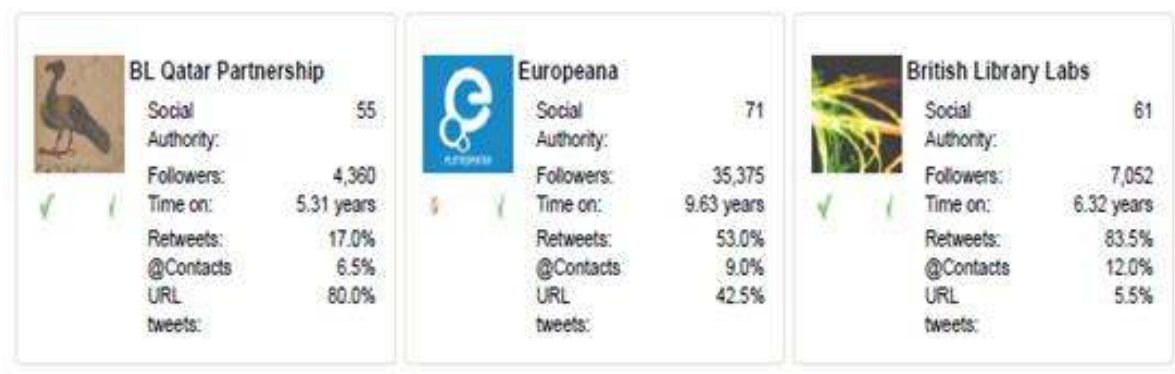

(The image copyright belongs to the author who compiled the image from publicly available data)

Figure 2. Followers of the three tweeter accounts

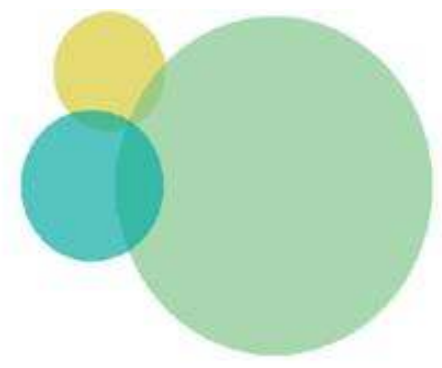

4,360 solowers of Bx catar 35,375 followers of Eurpeseanos 7,052 folowers of BQ Lates

followers ondy of Btostar. followers only of Europeansev. followers only of Blomar 8 followers onyly of
Europesassu, followess only of BLestar 8 BL_Labs. followers only of Europesnaeg s BL_Labs : followers of all three : comoined torar followers

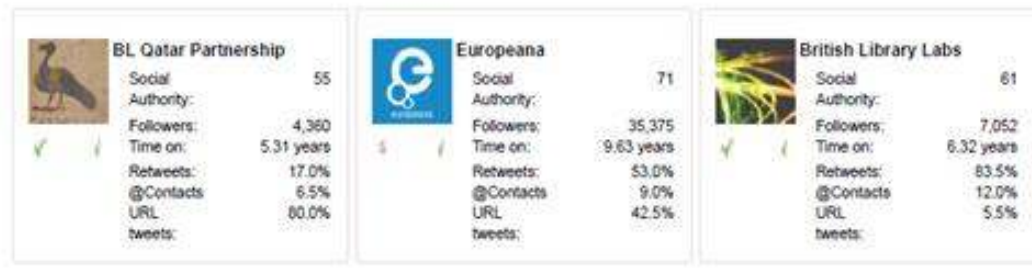

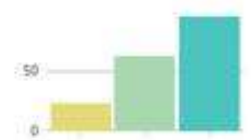

expoptinen \% rate

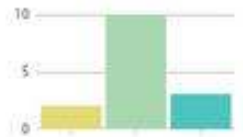

avg followers per dy

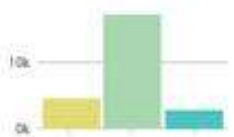

near weets

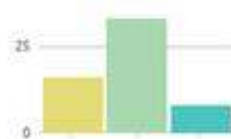

ang theets per week

(The image copyright belongs to the author who compiled the image from publicly available data)

11 After considering other factors, tweets that had images received more clicks, favourites, and retweets than the ones with no images. This outcome agrees with Stadd (2014) research that indicates that including images in tweets boosts engagement rate of the tweet. Adding an image in a tweet makes the tweet more conspicuous and attractive in the tweet stream, which makes it have more attention from the users. 
Hence, adding images in any tweet is an effective way of boosting engagement rate of the tweet.

12 Another finding was that tweets with links received more clicks and views. It generated more clicks and view for the QDL tweets, but it does not generate more retweets, favourites, and likes for QDL. Therefore, it shows that for QDL to improve its engagement rate they have to ensure that every tweet they make has images and short links like links that direct people to its website where more information about the posted item exists. Doing so, will give the users something interesting and new to retweet and share.

\section{Conclusion}

QDL is still expanding the use of its Twitter account, especially the community of followers. Although they have put some efforts, they still have to do a lot to attain their desired goals as far as social media marketing is concerned. Consequently, this paper has addressed the key issues that causes QDL to still lack behind in its Twitter engagement rate. It is evident that QDL has to add images and short links in every tweet it makes to get more retweets, likes, and favorites that will subsequently boost its Twitter engagement rate.

14 In addition, the paper finds it necessary for future research to investigate whether adding videos to QDL tweets would affect engagement rate and whether responses to user queries might have any impact on the engagement with QDL tweets. With social media presence being an essential component of the digital presence, we hope that these findings will inspire further observations and will improve the overall digital presence of QDL and will inform and strengthen the channels of digital publishing.

\section{BIBLIOGRAPHY}

Davies, Richard. "British Library Qatar Foundation Partnership.” Alexandria: The Journal of National and International Library and Information Issues, vol. 28, no. 1, Apr. 2018, pp. 5-12. doi: 10.1177/0955749018809565.

Demirbas, Murat, et al. "Crowd-Sourced Sensing and Collaboration Using Twitter." 2010 IEEE International Symposium on "A World of Wireless, Mobile and Multimedia Networks" (WoWMoM), IEEE, 2010, pp. 1-9. doi:10.1109/WOWMOM.2010.5534910.

Medawar, Katia, and Myrna Tabet. "Libraries in the State of Qatar: Current Situation and Future Outlook." Journal of Library Administration, vol. 56, no. 1, Jan. 2016, pp. 52-73. doi: 10.1080/01930826.2015.1113811.

Soboleva, Alena. Marketing with Twitter: Investigating Factors That Impact on the Effectiveness of Tweets. Western Sydney University, Apr. 2018, hdl.handle.net/1959.7/uws:47360. 
Stadd, Allison. "Tweets with photos drive much higher engagement across all metrics [research].” Ad Week, 2014, www.adweek.com/digital/tweets-with-photos/.

\section{ABSTRACTS}

Digital libraries often need to make tweets that will attract high engagement rate. To understand this factor in relation to Qatar Digital Library (QDL), this paper will draw a comparison of tweeter feeds of QDL, British Library Labs (BL Labs) as well as Europeana Digital Library. In doing so, the paper will try to establish the reasons behind low engagement rate in the QDL tweets. So, this paper will develop steps that QDL can take so that it can increase its current number of Twitter followers and increase the engagement rate of its users. The things that QDL is failing to address will be identified by comparing the best Twitter practices from BL Labs, and Europeana digital library to that of QDL. After identifying, a recommended practices for the QDL will be provided. The practices will mainly be meant to help QDL have better Twitter engagement rate.

\section{INDEX}

Keywords: Twitter, QDL, Qatar Digital Library, Europeana, BL Labs

\section{AUTHOR}

\section{MAHA ALSARRAJ}

Qatar National Library

malsarraj@qnl.qa 